\title{
Spillover Effect of Chinese Cross-Listed Companies across Shanghai, Hong Kong and US Markets
}

\author{
Bijing Li \\ College of Science, China Jiliang University, China \\ Tel: 86-571-8683-5708 E-mail: 1bj005@163.com
}

Ronghua Yi

College of Economics and Management, China Jiliang University, China

Tel: 86-571-8683-6203Ｅ-mail: yirh@cjlu.edu.cn

Roger Su

Faculty of Business and Law, Auckland University of Technology

Tel: 64-9921-9999-5058Ｅ-mail: roger.su@aut.ac.nz

Received: May 25, 2011

Accepted: July 5, $2011 \quad$ Published: November 1, 2011

doi:10.5539/ijef.v3n6p135

URL: http://dx.doi.org/10.5539/ ijef.v3n6p135

\begin{abstract}
This paper assesses the spillover effect of returns of ten Chinese cross-listed equities which are traded in Shanghai, Hong Kong and US markets simultaneously. We find a strong unidirectional spillover effect from US market to Shanghai market, however, a significant two-way influence exists between Hong Kong and US markets. When we use VAR modeling to exam the same-day effect, we find evidence that the effect of same-day return occurs from the Shanghai to Hong Kong market and from the Hong Kong to US market; however, there is no such effect from the Shanghai to US market.
\end{abstract}

Keywords: Spillover effect, Return, Cross-listed, Chinese equities, A shares, H shares, ADRs

\section{JEL classification: F3; G11; G15}

\section{Introduction}

Morana and Beltratti(2008) point out that financial markets integration could have eroded much of the gains from international diversification by making markets co-move more closely and enhancing spillovers. However, the spillover effects in international markets pose a challenge to investors who expect to reduce unsystematic risk from international diversified portfolios. The increasing number of cross-listed companies (one company is listed on two or more markets) may speed international integration; the number of cross-listed companies has grown significantly since the early 1990s. Bennett and Keller (1988) believe that the listing of stocks at multiple stock exchanges globally had added to integration of markets, with more and more studies now focussing on the spillover effects of cross-listed equities.

The purpose of this paper is to examine the return spillover effect of cross-listed Chinese equities which are cross-listed in the Shanghai, Hong Kong and US markets. When the Chinese economy grows rapidly, some Chinese companies need more capital to support their fast growth from domestic and foreign markets. When those Chinese firms are listed on different markets, some speculative investors wish to get arbitrage benefits from asynchronous price movements.

This research analyses all ten Chinese firms which are cross-listed on the Shanghai (A share), Hong Kong (H share) and the American Depository Receipts (ADRs) simultaneously. These days, the news and information transmits from one country to another within a short time horizon. It has become necessary to study the same-day effect on spillover effects among markets. The early opened market may have a strong influence for forthcoming opening markets. We examine the same-day price spillover of Chinese cross-listed equities with Vector Autoregressive (VAR) models developed by Singh, Kumar and Pandey (2009).

This paper is organized as follows: section 2 presents a literature review and a brief review of the Chinese 
cross-listed equities. Section 4 provides details of the employed methodology; and section 5 explains the empirical results and the final section concludes the whole research.

\section{Literature review}

The dramatically increasing numbers of cross-listed companies on international markets have made it necessary to consider where information is impounded into prices (Eun and Sabherwal, 2003). When Alaganar and Bhar (2002) studied Australian-American dual-listed stocks, they found unidirectional information flow from the US to Australian market. Eun and Sabherwal (2003) find that the prices are co-integrated and mutually adjusting between home and host markets for 62 cross-listed Canadian firms on the U.S. exchanges. Jaiswal-Dale and Jithendranathan (2009) analyzed daily price and volume data of 264 stocks from 26 countries that are traded in their home country and cross-listed outside their home market as depository receipts (DR), they found DR returns and volatilities are affected by the shocks in the markets where they are cross-listed controlling for domestic shocks. Contemporaneous and/or lagged shocks to the cross-listed markets are transmitted to domestic stock returns.

Hansda and Ray (2003) investigated ten Indian companies with floated ADRs, and found a strong correlation between the prices of the dually listed stocks, with the same bidirectional relation between domestic market and NASDAQ /New York Stock Exchange.

Some Chinese firms have been aggressive in seeking capital via foreign listings due to its rapid economic growth as well. Xu and Fung (2002) examine patterns of information flows for China-background stocks cross-listed on exchanges in Hong Kong and New York, and indicate significant mutual feedback of information between the two markets in terms of pricing and volatility. Stocks listed on the Hong Kong market appear to play a more significant role of information transmission in the pricing process, whereas stocks listed on the NYSE play a considerable role in volatility spillover. Kutan and Zhou (2006) believe that the Hong Kong market has the most significant impact on mean returns of the ADRs. After studying the stocks cross-listed on the New York Stock Exchange (NYSE) and the Stock Exchange of Hong Kong (SEHK), Su and Chong (2007) point out that the stock prices in these two exchanges are co-integrated and mutually adjusting.

\section{Research data}

Chinese equity markets have grown rapidly since the early 1990s when the Shanghai Stock Exchange and the Shenzhen Exchange were established. By the end of 2009, there were 1718 firms are listed on domestic A-share listing market. (Note 1) Due to significant demand of capital, some Chinese companies are also directly or cross listed on international markets. The major cross-listed international markets are the Hong Kong, Singapore and US markets. Today, a total of ten Chinese companies are simultaneously listed on the Shanghai, Hong Kong and U.S. markets in the form of A shares, $\mathrm{H}$ shares and ADRs respectively. Table 1 provides a list of these companies with additional information such as the code of the company on each of the exchanges, conversion ratio (number of $\mathrm{H}$ shares per ADRs) and the listing dates of A shares.

To investigate the same-day spillover effect of these ten cross-listed companies, we need to know opening and closing times in the three markets. Both local and GMT timings of Shanghai, Hong Kong and US market are provided in Table 2. China and Hong Kong are in the same time zone, while the US are not; during the daily opening to closing time in US market, it is night time in Asia. The Chinese market opens and closes 30 minutes earlier than the Hong Kong market; the US market opening time is 12.5 hours behind Hong Kong. We obtained daily opening and closing prices of A share, $\mathrm{H}$ share and ADR of these ten cross-listed firms from Yahoo Finance. Because $\mathrm{H}$ shares are quoted in Hong Kong dollars, ADRs in US dollars and A shares in RMB, we converted all into RMB basing on the daily spot exchange rate.(Note 2) Daily close-to-close and open-to-open returns of three classes of shares are computed by taking the log difference of close and open prices over the entire sample period respectively. We excluded weekends and holidays in three markets in calculating daily returns. In this sense, the returns are over a trading day and may cover more than one calendar day.

In the next section, we focus on the methodology incorporating the same day effect presented by Singh, Kumar and Pandey (2009) to test the spillover effect of returns of Chinese cross-listed firms.

\section{Methodology}

To examine the same-day spillover effect of returns of ten Chinese cross-listed stocks, we employ the vector autoregressive (VAR) which was used by Singh, Kumar and Pandey (2009). The VAR model thus estimates a dynamic simultaneous equation system; free of a priori restrictions on the structure of relationships; and the VAR is a good model to examine the spillover effect (Eun and Shim, 1989; Alaganar and Bhar, 2002; Hansda and Ray, 2003). The VAR model will be used to examine A shares, $H$ shares and the ADRs respectively. The VAR model employed in our study is as follows: 


$$
R_{i, t}=\delta_{i}+\sum_{i=1}^{p} \phi_{i, t} R_{i, t-i}+\sum_{j=1}^{l} \chi_{j, t} R_{j, t}+\sum_{j=1}^{k} \beta_{j, t} R_{j, t-i}+\varepsilon_{i, t}
$$

Where,

$R_{i, t}=\left(R_{A, t}, R_{H, t} R_{A D R s, t}\right)^{\prime}, R_{A, t} R_{H, t}, R_{A D R s, t}$ represents the return of A shares, $\mathrm{H}$ shares and the ADRs at time $t$,

$\delta_{i}$ and $\phi_{i}$ are $3 \times 1$ and $3 \times 3$ coefficient matrix respectively,

$p$ is the lag length, and

$\varepsilon_{i, t}$ is the $3 \times 1$ column vector of forecast errors.

' $l$ ' is the number of shares that open/close before the $i$ th share, and

$\mathrm{k}$ is the number of shares that open/close after the $i$ th share.

The three markets operate with different opening and closing times, thereby making return observations asynchronous. However, this VAR model can be used to examine the spillover effect of several markets with different opening/closing times Singh, Kumar and Pandey (2009). Here we perform the VAR model with exogenous variables for market returns and incorporated the same day effect of market returns which open/close before the market under consideration. For the markets which open/close before the market under examination, the same day returns of these markets are used as explanatory variables and those markets which open/close after, the one day lagged returns are used as explanatory variables. For example, while modeling $\mathrm{H}$ shares return, the same day returns of A shares and one day lagged return of ADRs are considered as explanatory variables.

\section{Empirical results}

To examine the spillover effect of returns of ten cross-listed Chinese companies' A shares, H shares and the ADRs, we use the daily return of open-to-open and close-to-close prices. We firstly employ the VAR model to exam the partial cross-correlation of three classes of shares with closing and opening prices respectively (see Table $3 \mathrm{a}$ and $3 \mathrm{~b}$ ). In Table 3a, the results show that the one day lag of the ADRs returns has a positive and statistically significant impact on the same period returns of A shares. It ranges between 0.0232 and 0.2360 . The influence return from the one day lag of $\mathrm{H}$ shares to A shares is smaller than from $\mathrm{H}$ shares to ADRs. We also find that there is a strong interaction between $\mathrm{H}$ shares and the ADRs in addition to their return persistence. In contrast, the influence return from one day lag of A shares is little. Two results are similar from both close-to-close and open-to-open series; these results indicate strong unidirectional spillover effect from US market to Shanghai market. However, we find a significant two-way influence between Hong Kong and New York markets (Xu and Fung, 2002; Su and Chong, 2007; Kutan and Zhou, 2006).

The three markets operate with different opening and closing times, thereby making return observations asynchronous; in order to show a clear picture, we also exam the same-day spillover effect of these Chinese cross-listed companies. Table $4 \mathrm{a}$ shows the return spillover of closing prices and Table $4 \mathrm{~b}$ shows the return spillover of opening prices.

From Table $4 \mathrm{a}$ and $4 \mathrm{~b}$, we find that the ADRs return is mainly influenced by $\mathrm{H}$ shares which trade before it, with no such effect from the same day return of A shares to the ADRs; which is similar to Hong Kong market (Kutan and Zhou, 2006). Both Table 4a and Table $4 \mathrm{~b}$ have similar results. As such, we believe there is a more significant same-day effect between Hong Kong- US than Shanghai-US markets.

\section{Conclusions}

This study examines the spillover effect of return of ten Chinese cross-listed stocks across Shanghai, Hong Kong and US markets. Different to previous literatures which mainly focus on the information flow of China-background stocks which are cross-listed in Hong Kong and US markets, we analyze the spillover effect across three markets, Shanghai, Hong Kong and US by using the daily prices on stock by stock basis. We find a strong unidirectional spillover effect from US market to Shanghai market while a significant two-way influence exists between the Hong Kong and New York markets. Furthermore, we find that the same day return effect occurs from Shanghai to Hong Kong market and from Hong Kong to US market, with no such effect from Shanghai to US market.

Cross-listed stocks are the important bridges connecting several stock markets and contribute to the interdependency of the markets (Wei, Lui, Yang, and Cheung, 1995). We believe that our study has value for both policymakers and 
investors in making financial decisions. And, this paper can also help investors and other academic people to better understand spillover effect between China and other markets. When any future academic research focuses on spillover effect of cross-listed equities, this paper may be considered in their literature reviews.

\section{Acknowledgment}

The authors appreciate the support from National Natural Science Foundation of China (NSFC) under project 70873115 .

We are also thankful for the funding provided by Key Universities Research Institute of Humanities and Social Sciences in Zhejiang Province, China. Standardization and Intellectual Property Management.

\section{References}

Alaganar, V.T. \& Bhar, R. (2002). Information and volatility linkage under external shocks: evidence from dually listed Australian stocks. International Review of Financial Analysis 11, 59-71. http://dx.doi.org/10.1016/S1057-5219(01)00070-9

Bennett, P. \& Keller, J. (1988). The International transmission of stock price disruption in October 1987. Federal Reserve Bank of New York Quarterly Review 13, 17-33.

Eun, C.S. \& Shim, S. (1989). International transmission of stock market movements. The Journal of financial and quantitative analysis 24, 241-256. http://dx.doi.org/10.2307/2330774

Eun, C.S. \& Shim, S. (2003). Cross-border listings and price discovery: evidence from U.S.-listed Canadian stocks. Journal of Finance 58, 549-574. http://dx.doi.org/10.1111/1540-6261.00537

Hansda, S.K. \& Ray, P. (2003). Stock market integration and dually listed stocks: Indian ADR and Domestic Stock Prices. Economic and Political Weekly 38(8), 22-28.

Jaiswal-Dale, A. \& Jithendranathanb, T. (2009). Transmission of shocks from cross-listed markets to the return and volatility of domestic stocks. Journal of Multinational Financial Management 19(5), 395-408. http://dx.doi.org/10.1016/j.mulfin.2009.07.005

Kutan, A.M. \& Zhou, H. (2006). Determinants of returns and volatility of Chinese ADRs at NYSE. Journal of Multinational Financial Management 16, 1-15. http://dx.doi.org/10.1016/j.mulfin.2005.02.003

Morana, C. \& Beltratti, A. (2008). Comovements in international stock markets. Journal of International Financial Markets, Institutions and Money18, 31-45. http://dx.doi.org/10.1016/j.intfin.2006.05.001

Pukthuanthong, K. \& Roll, R. (2009). Global market integration: An alternative measure and its application. Journal of Financial Economics 94, 214-232. http://dx.doi.org/10.1016/j.jfineco.2008.12.004

Singh, P., Kumar, B. \& Pandey, A. (2009). Price and volatility spillover across North American, European and Asian stock markets. International Review of Financial Analysis 19(1), 55-64. http://dx.doi.org/10.1016/j.irfa.2009.11.001

$\mathrm{Su}$, Q. \& Chong, T.T.L. (2007). Determining the contributions to price discovery for Chinese cross-listed stocks. Pacific-Basin Finance Journal 15, 140-153. http://dx.doi.org/10.1016/j.pacfin.2006.07.002

Wei, K., Lui, Y., Yang, C. \& Cheung, G. (1995). Volatility and price change spillover effects across the developed and emerging markets. Pacific Basin Finance Journal 3, 113-136. http://dx.doi.org/10.1016/0927-538X(94)00029-7

Xu, X.E. \& Fung, H.G. (2002). Information flows across markets: evidence from China-backed stocks dual-listed in Hong Kong and New York. The Financial Review 37, 563-588. http://dx.doi.org/10.1111/1540-6288.00029

\section{Notes}

Note 1. The data are collected from www.csrc.gov.cn.

Note 2. The exchange rates are from http://www.federalreserve.gov/releases. 
Table 1. Cross-listed Chinese Companies in Shanghai, Hong Kong and US

\begin{tabular}{|l|l|l|l|l|l|}
\hline Company name & A code & H code & ADRs code & Ratio (share/ADRs) & Listing date of A share \\
\hline Sinopec Shanghai Petrochemical Co. Ltd & 600688 & 0338 & SHI & $1: 100$ & $1993-11-8$ \\
\hline China Eastern Airlines Corp.Ltd & 600115 & 0670 & CEA & $1: 100$ & $1997-11-5$ \\
\hline Yanzhou Coal Mining Co. Ltd & 600188 & 1171 & YZC & $1: 10^{*}$ & $1998-7-1$ \\
\hline China Petroleum \& Chemical Corp & 600028 & 0386 & SNP & $1: 100$ & $2001-8-8$ \\
\hline Huaneng Power International Inc & 600011 & 0902 & HNP & $1: 50$ & $2001-12-6$ \\
\hline China Southern Airlines Co.Ltd & 600029 & 1055 & ZNH & $1: 50$ & $2003-7-25$ \\
\hline Guangshen Railway Co. Ltd & 601333 & 0525 & GSH & $1: 50$ & $2006-12-22$ \\
\hline China Life Insurance & 601628 & 2628 & LFC & $1: 15$ & $2007-1-9$ \\
\hline Aluminum Corp. of China Ltd & 601600 & 2600 & ACH & $1: 25$ & $2007-4-30$ \\
\hline Petrochina Co. Ltd & 601857 & 0857 & PTR & $1: 100$ & $2007-11-5$ \\
\hline
\end{tabular}

Asterisk (*) indicates the convert ratio of Yanzhou Coal Mining Co. Ltd changed from 50 to 10 shares per ADRs since June 6, 2008.

Table 2. A share, H Share and ADRs opening and closing time

\begin{tabular}{|c|c|c|c|c|c|}
\hline \multirow{2}{*}{ Class of listing } & Venue of listing & \multicolumn{2}{|c|}{ Local time } & \multicolumn{2}{|c|}{ GMT } \\
\cline { 3 - 6 } & & Open & Close & Cpen & $01: 30$ \\
\hline A shares & Shanghai & $09: 30$ & $15: 00$ & $07: 00$ \\
\hline H shares & Hong Kong & $10: 00$ & $16: 00$ & $02: 00$ & $08: 00$ \\
\hline ADRs & U.S. & $09: 30$ & $16: 00$ & $14: 30$ & $21: 00$ \\
\hline
\end{tabular}

Table 3a. The results of partial cross-correlation of A share, H share and ADR with close-to-close prices.

\begin{tabular}{|c|c|c|c|c|c|c|c|c|c|c|c|}
\hline & Code & SHI & CEA & YZC & SNP & HNP & $\mathrm{ZNH}$ & GSH & LFC & $\mathrm{ACH}$ & PTR \\
\hline \multirow{3}{*}{ A Shares } & A shares & $0.0107^{* *}$ & 0.0859 & -0.0229 & -0.0457 & $-0.0043^{* *}$ & 0.0411 & -0.1124 & $-0.0393 * *$ & $0.0037^{* *}$ & $-0.0212 * *$ \\
\hline & $\mathrm{H}$ shares & $0.0048^{* *}$ & -0.0514 & -0.0057 & $0.0193 *$ & 0.0045 & $-0.0098 * *$ & -0.0933 & -0.1467 & $-0.0488 * *$ & -0.0932 \\
\hline & ADRs & 0.0232 & 0.1147 & 0.0732 & 0.0723 & 0.0900 & 0.1666 & 0.1125 & 0.2360 & 0.1774 & 0.1823 \\
\hline \multirow{3}{*}{ H Shares } & A shares & $-0.0003 * *$ & 0.0623 & 0.0310 & $0.0523 *$ & $-0.0190 * *$ & 0.0509 & $-0.0355^{* *}$ & $0.0476^{* *}$ & $-0.0322 * *$ & 0.0159 ** \\
\hline & $\mathrm{H}$ shares & -0.2521 & -0.1831 & -0.1460 & 0.2196 & -0.1059 & -0.2021 & -0.2044 & -0.3709 & -0.2437 & -0.3124 \\
\hline & ADRs & 0.3321 & 0.2586 & 0.2730 & 0.2520 & $0.2462^{* *}$ & 0.3213 & 0.3561 & 0.3550 & 0.4853 & 0.4234 \\
\hline \multirow{3}{*}{ ADRs } & A shares & $0.0501 * *$ & $0.02674^{* *}$ & 0.0201 & $-0.0480 *$ & $-0.0293 * *$ & $0.0353 * *$ & $-0.0496 * *$ & $0.0707 *$ & $0.0122 * *$ & $-0.0108 * *$ \\
\hline & $\mathrm{H}$ shares & 0.0956 & 0.1492 & 0.1550 & $0.2869^{*}$ & -0.0038 & 0.1021 & 0.1037 & $-0.0132 * *$ & $0.0380^{* *}$ & $0.0666^{* *}$ \\
\hline & ADRs & -0.0881 & -0.0927 & -0.0870 & $-0.2124 * *$ & $-0.0372^{*}$ & -0.1034 & -0.1526 & -0.1827 & $-0.0499 * *$ & -0.1143 \\
\hline
\end{tabular}

$*(* *)$ denotes rejection significance at the $5 \%(10 \%)$ level.

Table 3b. The results of partial cross-correlation of A share, $\mathrm{H}$ share and ADR with open-to-open prices.

\begin{tabular}{|c|c|c|c|c|c|c|c|c|c|c|c|}
\hline & Code & SHI & CEA & $\mathrm{YZC}$ & SNP & HNP & $\mathrm{ZNH}$ & $\mathrm{GSH}$ & LFC & $\mathrm{ACH}$ & PTR \\
\hline \multirow{3}{*}{ A Shares } & A shares & -0.0367 & -0.0545 & -0.1038 & $-0.0806^{*}$ & $-0.0197 * *$ & $-0.0344 * *$ & -0.1476 & -0.0759 & $-0.0013 * *$ & $0.0401 * *$ \\
\hline & $\mathrm{H}$ shares & -0.0577 & -0.0545 & -0.0422 & $0.0250^{* *}$ & $0.0221 * *$ & $-0.0379 *$ & -0.0884 & -0.2584 & -0.1336 & -0.1193 \\
\hline & ADRs & 0.1658 & 0.2292 & 0.1770 & $0.3133^{*}$ & 0.1146 & 0.3341 & 0.2384 & 0.6108 & 0.3557 & 0.3130 \\
\hline \multirow{3}{*}{ H Shares } & A shares & $0.0181 * *$ & 0.0563 & 0.0399 & $0.0285^{*}$ & $-0.0196^{* *}$ & $0.0198^{* *}$ & $0.0406^{* *}$ & 0.1003 & $0.0700^{*}$ & 0.1294 \\
\hline & $\mathrm{H}$ shares & -0.3360 & -0.4081 & -0.3054 & 0.3673 & -0.1544 & -0.3699 & -0.3104 & -0.4925 & -0.4565 & -0.3982 \\
\hline & ADRs & 0.6875 & 0.7679 & 0.7177 & 0.6996 & 0.3767 & 0.7054 & 0.5756 & 0.6099 & 0.7033 & 0.6096 \\
\hline \multirow{3}{*}{ ADRs } & A shares & $0.0237 *$ & $0.0144 * *$ & $-0.0016^{* *}$ & $0.0370^{*}$ & $-0.0050^{* *}$ & $-0.0029 * *$ & $0.0132 * *$ & $0.0361 * *$ & $-0.0440 * *$ & $0.0934 * *$ \\
\hline & $\mathrm{H}$ shares & $0.0270 *$ & -0.0471 & $-0.0197 * *$ & -0.0417 & -0.0514 & -0.0795 & $0.0494 * *$ & $-0.0751^{*}$ & -0.1055 & $-0.0801 * *$ \\
\hline & ADRs & $0.0019^{* *}$ & 0.1156 & 0.1226 & -0.0262 & $-0.0240^{* *}$ & 0.0853 & -0.1000 & -0.0950 & 0.0941 & $-0.0454^{* *}$ \\
\hline
\end{tabular}

$*(* *)$ denotes rejection significance at the $5 \%(10 \%)$ level. 
Table 4a. The results of same-day spillover effect by VAR model with close-to-close price returns

\begin{tabular}{|c|c|c|c|c|c|c|c|c|c|c|c|}
\hline & Code & SHI & CEA & YZC & SNP & HNP & $\mathrm{ZNH}$ & GSH & LFC & $\mathrm{ACH}$ & PTR \\
\hline \multirow{6}{*}{$\mathrm{H}$ shares } & AR1 & -0.328 & -0.188 & -0.175 & -0.178 & -0.106 & -0.23 & -0.36 & -0.385 & -0.291 & -0.368 \\
\hline & AR2 & -0.138 & -0.094 & -0.086 & -0.062 & -0.048 & -0.161 & -0.172 & -0.111 & -0.149 & $-0.073 * *$ \\
\hline & AR3 & -0.084 & $-0.005^{* *}$ & -0.096 & -0.079 & $0.002 * *$ & -0.059 & -0.227 & $-0.052 * *$ & -0.068 & $-0.077^{* *}$ \\
\hline & AR4 & -0.037 & $-0.029 * *$ & -0.057 & -0.084 & $0.010 * *$ & -0.065 & -0.119 & -0.077 & $-0.023 * *$ & -0.091 \\
\hline & A shares $(t)$ & 0.164 & 0.407 & 0.263 & 0.425 & 0.114 & 0.377 & 0.265 & 0.495 & 0.412 & 0.478 \\
\hline & $\operatorname{ADRs}(\mathrm{t}-1)$ & 0.397 & 0.233 & 0.281 & 0.142 & 0.234 & 0.285 & 0.437 & 0.263 & 0.427 & 0.382 \\
\hline \multirow{6}{*}{ ADRs } & AR1 & -0.563 & 0.019 & -0.419 & -0.745 & -0.165 & -0.502 & -0.708 & -0.756 & -0.746 & -0.777 \\
\hline & AR2 & -0.458 & 0.862 & -0.286 & -0.539 & -0.15 & -0.342 & -0.569 & -0.597 & -0.627 & -0.636 \\
\hline & AR3 & -0.24 & -0.498 & -0.108 & -0.353 & $0.003 * *$ & -0.168 & -0.272 & -0.368 & -0.374 & -0.411 \\
\hline & AR4 & -0.151 & -0.418 & $-0.035 *$ & -0.166 & $-0.011 * *$ & $-0.032^{* *}$ & -0.084 & -0.179 & -0.177 & -0.129 \\
\hline & A shares $(t)$ & 0.021 & $-0.243 * *$ & 0.043 & $0.003 * *$ & 0.098 & $0.026 * *$ & $0.015^{* *}$ & $-0.018 * *$ & $-0.019 * *$ & $-0.013 * *$ \\
\hline & $H$ shares $(t)$ & 0.846 & -0.131 & 0.822 & 0.957 & 0.407 & 0.815 & 0.853 & 0.878 & 0.902 & 0.87 \\
\hline
\end{tabular}

Table $4 \mathrm{~b}$. The results of same-day spillover effect by VAR model with open-to-open price returns

\begin{tabular}{|c|c|c|c|c|c|c|c|c|c|c|c|}
\hline & Code & SHI & CEA & $\mathrm{YZC}$ & SNP & HNP & $\mathrm{ZNH}$ & GSH & LFC & $\mathrm{ACH}$ & PTR \\
\hline \multirow{6}{*}{$\mathrm{H}$ shares } & AR1 & -0.552 & -0.569 & -0.446 & -0.744 & -0.189 & -0.521 & -0.726 & -0.644 & -0.768 & -0.765 \\
\hline & AR2 & -0.356 & -0.379 & -0.283 & -0.531 & -0.061 & -0.27 & -0.492 & -0.245 & -0.506 & -0.393 \\
\hline & AR3 & -0.248 & -0.209 & -0.14 & -0.349 & $-0.033^{* *}$ & -0.185 & -0.312 & -0.104 & -0.357 & -0.291 \\
\hline & AR4 & -0.119 & -0.092 & -0.115 & -0.169 & $0.010^{* *}$ & -0.125 & -0.124 & -0.085 & -0.207 & -0.172 \\
\hline & A shares $(\mathrm{t})$ & 0.076 & 0.195 & 0.14 & 0.096 & 0.068 & 0.228 & 0.149 & 0.284 & 0.124 & 0.181 \\
\hline & $\operatorname{ADRs}(\mathrm{t}-1)$ & 0.784 & 0.75 & 0.715 & 0.795 & 0.38 & 0.648 & 0.761 & 0.544 & 0.787 & 0.762 \\
\hline \multirow{6}{*}{ ADRs } & AR1 & -0.651 & -0.551 & -0.446 & -0.664 & -0.159 & -0.358 & -0.681 & -0.818 & -0.728 & -0.754 \\
\hline & AR2 & -0.401 & -0.351 & -0.269 & -0.439 & -0.09 & -0.152 & -0.383 & -0.585 & -0.582 & -0.577 \\
\hline & AR3 & -0.251 & -0.178 & -0.113 & -0.302 & $-0.005^{* *}$ & -0.051 & -0.304 & -0.374 & -0.358 & -0.321 \\
\hline & AR4 & -0.082 & -0.085 & -0.052 & -0.154 & $-0.021 * *$ & $-0.006^{* *}$ & -0.137 & -0.214 & -0.198 & -0.181 \\
\hline & A shares $(\mathrm{t})$ & $0.004^{* *}$ & $0.031 *$ & 0.046 & $-0.009 * *$ & 0.049 & $0.035^{* *}$ & $0.007^{* *}$ & $-0.004 * *$ & $-0.017^{* *}$ & $-0.015^{* *}$ \\
\hline & $\mathrm{H}$ shares $(\mathrm{t})$ & 0.74 & 0.709 & 0.674 & 0.8 & 0.315 & 0.567 & 0.782 & 0.844 & 0.9 & 0.852 \\
\hline
\end{tabular}

*(**) denotes rejection significance at the $5 \%(10 \%)$ level 